\title{
Psychological trauma of primary hypertension and the best treating choice.
}

\author{
Wei Zhang ${ }^{1}$, Hui-Jian Deng ${ }^{2}$, Li-Mei Xu' ${ }^{1 *}$, Bin Han', Yu-Liang Zhou ${ }^{1}$, Zhi-Yong Li ${ }^{2}$, Qun Lu ${ }^{2}$ \\ ${ }^{1}$ First Affiliated Hospital of Guangdong Pharmaceutical University, Guangzhou, China \\ ${ }^{2}$ Clinical Medical School of Guangdong Pharmaceutical University, Guangzhou, China
}

\begin{abstract}
Objective: To explore the relationship among the age, blood pressure and psychological factors and provide theoretical basis for hypertension by comprehensive evaluation method.

Method: The 956 hypertension patients were grouped according to different blood pressure level, which were from the Department of Cardiology in a first class Grade A Hospital in Beijing. We measured their blood pressure index, Eysenck Personality Questionnaire (EPQ), self-rating anxiety scale and self-rating depression scale. The physical and psychological characteristics were observed at different levels in patients with hypertension.

Results: 1) There is statistical significance in BAI score among different hypertension degree groups, $F=18.437, P=0.0001 ; 2)$ There is statistical significance in $B D I$ score among different hypertension degree groups, $\mathrm{F}=18.437, \mathrm{P}=0.0001 ; 3)$ There is statistical significance in $\mathrm{N}$ score among different age groups, $F=16.541, P=0.0001 ; 4)$ According to results, the first level was the best treatment range for hypertension.

Conclusion: 1) If the hypertension level is higher, the psychological symptoms will be more severe. The psychological symptoms will not be obvious unless the hyper-tensing level is over grade 2 . We considered that the first level is the best stage for treating the hypertension; 2) For the hypertension patients in this research, the risk factors of anxiety and depression are systolic blood pressure and $\mathbf{N}$ norm. Reducing systolic blood pressure and improving emotional stability can relieve their anxiety and depression.
\end{abstract}

Keywords: Primary hypertension, Personality, Psychological trauma, Treat timing.

Accepted on April 19, 2018

\section{Introduction}

Hypertension is a kind of chronic and systemic diseases with the symptom of rising arterial blood pressure, and functional or organic changes in heart, brain, kidney and retina. Blood pressure includes systolic blood pressure and diastolic blood pressure. Hypertension shows constantly higher blood pressure than $140 / 90 \mathrm{~mm}$ mercury column. Primary hypertension is the most common accounting for $90-95 \%$ in all the hypertension cases [1]. Generally, blood pressure rises along with the increase of age. According to a survey on the nutrition and health condition organized by the Ministry of Health of PRC, it involved 270,000 residents in 2002, and its prevalence was $49 \%$ or over among Chinese people aged 60 [2]. Both genetic and environmental factors could contribute to the hypertension. $\mathrm{Wu}$ et al. found that the incidence rate of hypertension was higher in patients with severe depression and its medical history one year longer than the general $(21.21 \%$ : $13.28 \%$, the risk ratio $1.22 ; 95 \% \mathrm{CI}, 1.17-1.28$ ). Nearly all MDD patients suffered hypertension in each age group and sex. From 2006 to 2008, hypertension patients with MDD had a higher incidence rate than the general each year. (3.96\%: $2.90 \%$, risk ratio 1.19 ; 95\% CI, 1.08-1.31) [3]. Ginty et al. have done some researches on Dutch Famine Birth cohort study, and they found that the blood pressure was correlated to anxiety and depression in hypertension patients with more than 5-y ( $\mathrm{n}=455,238$ women), but the specific mechanism has been not elucidated yet [4]. Ford et al. have conducted a 16-y longitudinal study (1948-1964) on 1190 medical college students, and found that the RR value of coronary heart disease was $2.12(95 \% \mathrm{CI}$, 1.24-3.63) in male patients with depression. The relative risk of suffering myocardial infarction was 2.12 (95\% CI, 1.11-4.06) $[5]$.

Depression and anxiety were the highly risk factors of hypertension that was the high risk factor of cardiovascular and cerebrovascular diseases. The personality of hypertension patients and the changes of their emotional state could lead to the fluctuation of blood pressure causing serious consequences. The age distribution was closely correlated with the anxiety, depression state as well as the distribution of personality characteristics. In clinical, patients with hypertension often suffered from psychological symptoms, and they were also troubled by these symptoms causing declining of their quality of life. What's more, their state can lead to the fluctuation of mood, so the anti-hypertensive efficacy was reduced. Hypertensive patients would not all suffered from 
psychological symptoms, and psychological symptoms were not appeared in patients with blood pressure in all grade. Therefore, it was meaningful to eliminate psychological trauma and relapses of hypertension controlled the blood pressure under psychological trauma. It has practical significance to reducing their interaction, which is the aim of the current study.

\section{Materials and Methods}

\section{Subjects}

Patients searching for initial medical treatment are collected from the Department of Cardiology in a first class and Grade A Hospital, between July 2011 and October 2013.

Inclusion standard: 1) Every case should have complete data of demography and medical history; 2) Every case should meet the diagnostic criterion of hypertension; 3) Patients do not suffer from brain injury, organic brain disease and psychiatric disorder; 4) Patients do not suffer from mental deficiency and are able to complete the psychological test with the assistance of researchers; 5) Informed consent.

Exclusion standard: 1) Patients are with serious illness in their heart, liver, kidney, brain, lungs and alimentary tract; 2) Patients are with tumor and other malignant illnesses; 3) Patients don't want to participate in the research.

The 1000 hypertension patients meet the criteria in this study after psychological test and screening of clinical data. After exclusions of patients with results omission or casual answering, 956 people were regarded as valid subjects, in which 546 were males, 410 females, 223 unmarried, and the valid rate was $95.60 \%$. They were aged 20 to 74 y old and average age was $56.81 \pm 6.21$. The research met the ethic criteria of Declaration of Helsinki in 1964.

\section{Methods}

After admission into hospital, patients were examined with a series of tests including blood RT, urine RT, biochemical test for liver function, blood coagulation factor test, 8 virus RTs, EKG and lung function test.

BP index measurement: data was obtained from the average of 3 times test of resting patients who are in their initial medical treatment. Then data was graded according to severity.

Recorded the systolic pressure and diastolic pressure of all groups, then they were graded according to the criteria suggested by Chinese Hypertension Treatment Guidelines.

Systolic BP $\geq 140$; Diastolic BP $\geq 90$; Unit: mm Hg.

Level I hypertension (mild) systolic BP 140 159 diastolic BP 90 99;

Level II hypertension (moderate) systolic BP 140 159 diastolic BP 90 99;

Level III hypertension (severe) systolic BP $\geq 180$ diastolic BP $\geq 110$
Patients were divided into three groups according to blood pressure classification: level 0 (normal group), level I, level II, level III.

\section{Psychological tests}

Beck Anxiety Inventory (BAI): A 21-question, 4-grade assessment system was used to assess the degree of anxiety caused by various anxiety symptoms. This assessment system was designed for adults with anxiety symptoms and could relatively precise reflect of the subjective experience to the tests.

Reliability: 80 healthy people and 60 patients with anxiety disorder were tested by BAI, and then the results were analyzed using t-test showing that the two groups have significant difference $(\mathrm{P}<0.01)$.

Validity: 60 anxiety disorder patients were tested by BAI and SAS (Self-rating Anxiety Scale, designed by Zung in 1971), and then correlation analysis was conducted, in which the correlation coefficient was 0.828 . The result indicated that the sum of objective assessments in BAI and SAS showed positive correlation, and guaranteed the validity of BAI in clinical application [6].

In Beck Depression Inventory (BDI): Beck (1967), the depression was divided into 21 'symptom -attitude categories', in which every clause stranded for one category. These categories included mood, pessimism, frustration, dissatisfaction, feeling of guilty, feeling of punishment, selfhating, self-blaming, suicidal tendency, wailing, irritability, social withdraw, hesitation, body image distortion, activity depression, sleeping disorder, fatigue, loss of appetite, loss of body weight, preoccupation and sexual hypo-activity. Its aim was to assess the severity of depression. Reliability: internal consistency: the odd split-half reliability coefficient was 0.86 (Spearman-Brown correlation coefficient is 0.93).

Retest consistency: The stable coefficient of this diagram was usually $0.70-0.80$ in several weeks.

Convergent validity: BDI had significant co-relationship with clinical depression assessment; the correlative coefficient was $0.60-0.90$.

Discrimination validity: BDI had more significant corelationship with clinical depression assessment than anxiety (0.14) [6].

Eysenck Personality Questionnaire (EPQ): Adolescent version including 74 questions was designed for patients younger than $16 \mathrm{y}$ old, while the adult version for patients over 16 (16 y old patients included). The reliability and validity of their diagram were high: the split-half reliability of this diagram was $0.34 \sim 0.77$, retest reliability was $0.67 \sim 0.92$, criterion validity was $0.3 \sim 0.45$ [7].

\section{Statistical methods}

The SPSS17.0 software was used for statistical analysis. The Spearman correlation and analysis of covariance were used to 
compare difference between two groups, if there is dependency among the high-risk age group, mental factors and personality traits. If $\mathrm{p}<0.05$, the difference was considered as statistical significance.

\section{Results}

\section{Analysis of covariance for different classification about anxiety mood in hypertension patients}

As shown in Table 1, there was statistical significance in BAI score among different hypertension degree groups, $\mathrm{F}=16.538$, $\mathrm{P}=0.0001$; the multiple comparisons showed that (LSD): the BAI sore was statistical significance between Group 0 and group I III. Covariate of age had little influence on the anxiety scores. It also suggested that there was no statistical significance in BAI score among different age groups. $\mathrm{F}=2.035, \mathrm{P}=0.2801$; these results indicated that grade 1 could induce anxiety easily in blood pressure classification for hypertension patients.

Table 1. Analysis of covariance for different classification about hypertension patients' anxiety mood $(n=956)$.

\begin{tabular}{|c|c|c|c|c|c|}
\hline & Item & $\mathrm{n}$ & BAl score & $\mathbf{F}$ & $\mathbf{P}$ \\
\hline \multirow{4}{*}{$\begin{array}{l}\text { Hypertension } \\
\text { degree }\end{array}$} & 0 & 208 & $39.25 \pm 5.41$ & \multirow{4}{*}{16.538} & \multirow{4}{*}{0.0001} \\
\hline & 1 & 272 & $46.25 \pm 7.23^{\square, \Delta}$ & & \\
\hline & $\|$ & 294 & $49.34 \pm 8.35^{\Delta \Delta}$ & & \\
\hline & III & 182 & $57.43 \pm 7.03^{* *}$ & & \\
\hline \multirow{3}{*}{ Age } & $20-40 y$ & 225 & $42.05 \pm 6.25$ & \multirow{3}{*}{2.035} & \multirow{3}{*}{0.2801} \\
\hline & $40.5-60 y$ & 383 & $44.27 \pm 6.34$ & & \\
\hline & $\geq 60 y$ & 361 & $46.60 \pm 4.57$ & & \\
\hline
\end{tabular}

*The comparison between group I and other groups: ${ }^{*} \mathrm{P}<0.05,{ }^{* *} \mathrm{P}<0.01 ;{ }^{\Delta}$ The comparison between group II and other groups: $\Delta \mathrm{P}<0.05, \Delta \Delta \mathrm{P}<0.01$; $\square$ The comparison between group III and other groups: ${ }^{\mathrm{P}}<<0.05,{ }^{a} \mathrm{P}<0.01$.

\section{Analysis of covariance for different classification about depress mood in hypertension patients}

It could be found from Table 2 that there was statistical significance in BDI score among different hypertension degree groups; $\mathrm{F}=18.437, \mathrm{P}=0.0001$. The multiple comparisons showed that (LSD) the BAI sore showed statistical significance between group 0 and group I III. Covariate of age had little influence on the anxiety scores. It also revealed that there was no statistical significance in BAI score among different age groups, $\mathrm{F}=1.085, \mathrm{P}=05721$; these results indicated grade 1 could induce anxiety easily in blood pressure classification for hypertension patients.

Table 2. Analysis of covariance for different classification about hypertension patients' depression mood $(n=956)$.

\begin{tabular}{|c|c|c|c|c|c|}
\hline & Item & $\mathbf{n}$ & BDI score & $\mathbf{F}$ & $\mathbf{P}$ \\
\hline Hypertension degree & 0 & 208 & $7.23 \pm 3.61$ & 18.437 & 0.0001 \\
\hline
\end{tabular}

\begin{tabular}{|c|c|c|c|c|c|}
\hline & 1 & 272 & $12.25 \pm 3.46^{* *}$ & & \\
\hline & II & 294 & $15.38 \pm 4.27^{* *}$ & & \\
\hline & III & 182 & $16.49 \pm 4.35^{* *}$ & & \\
\hline & $20-40 y$ & 208 & $12.23 \pm 2.51$ & & \\
\hline Age & $40.5-60 y$ & 272 & $14.14 \pm 2.34$ & 1.085 & 0.5721 \\
\hline & $\geq 60 y$ & 294 & $16.48 \pm 3.57$ & & \\
\hline
\end{tabular}

The comparison between group I and other groups: ${ }^{*} \mathrm{P}<0.05,{ }^{* *} \mathrm{P}<0.01 ;{ }^{\Delta}$ The comparison between group II and other groups: $\Delta P<0.05, \Delta \Delta P<0.01$; $\square$ The comparison between group III and other groups: ${ }^{\mathrm{P}}<0.05,{ }^{\mathrm{a}} \mathrm{P}<0.01$.

\section{One-way ANOVA analysis of introversion/ extraversion in different classification hypertension patients groups}

It could be seen from Table 3 that there was no statistical significance in $\mathrm{E}$ score among different groups, $\mathrm{F}=2.437$, $\mathrm{P}=0.230$.

Table 3. One-way classification ANOVA results for introversion/ extraversion in different classification about hypertension patients' groups $(n=956)$.

\begin{tabular}{|c|c|c|c|c|c|}
\hline & Item & $\mathbf{n}$ & E (Intro/extroversion) & $\mathbf{F}$ & $\mathbf{P}$ \\
\hline \multirow{4}{*}{ Hypertension degree } & 0 & 208 & $42.36 \pm 14.23$ & \multirow{4}{*}{2.437} & \multirow{4}{*}{0.23} \\
\hline & I & 272 & $43.34 \pm 15.25$ & & \\
\hline & II & 294 & $47.53 \pm 20.45$ & & \\
\hline & III & 182 & $55.17 \pm 22.57$ & & \\
\hline
\end{tabular}

\section{One-way ANOVA analysis of introversion/ extraversion in different classification hypertension patients groups}

From Table 4, there was statistical significance in $\mathrm{N}$ score among different age groups, $\mathrm{F}=16.541, \mathrm{P}=0.0001$; the multiple comparison (LSD) showed that there was statistical significance in standard score of $\mathrm{N}$ between group 0 and group II III; the differences in $\mathrm{N}$ score between group II III were statistical significance. These results indicated that grade 2 could induce mood fluctuate easily in blood pressure classification for hypertension patients.

Table 4. One-way classification ANOVA results for emotional stability-instability in different classification about hypertension patients' groups $(n=956)$.

\begin{tabular}{|c|c|c|c|c|c|}
\hline & Item & $\mathbf{n}$ & $\begin{array}{l}\mathbf{N} \quad \text { (Emotional } \\
\text { stability-instability) }\end{array}$ & $\mathbf{F}$ & $\mathbf{P}$ \\
\hline \multirow{4}{*}{$\begin{array}{l}\text { Hypertension } \\
\text { degree }\end{array}$} & 0 & 208 & $43.45 \pm 9.48$ & \multirow{4}{*}{16.571} & \multirow{4}{*}{0.0001} \\
\hline & I & 272 & $45.43 \pm 10.25$ & & \\
\hline & II & 294 & $66.42 \pm 13.27^{\square}$ & & \\
\hline & III & 182 & $69.75 \pm 12.18^{* *}$, & & \\
\hline
\end{tabular}


The comparison between group I and other groups: ${ }^{*} \mathrm{P}<0.05,{ }^{* *} \mathrm{P}<0.01$; $\triangle$ The comparison between group II and other groups: $\triangle P<0.05, \Delta \Delta P<0.01$; The comparison between group III and other groups: ${ }^{\circ}<0.05$, ${ }^{\circ} \mathrm{P}<0.01$.

\section{Relevant analysis of systolic pressure, diastolic pressure, anxiety, depression and personality in different patients from different age groups}

Based on effect size of this index, the weight for BAI relapse was 0.366 , and the weight for BDI was 0.280 , and the weight for the standard score of $\mathrm{N}$ was 0.354 .

It can be calculated that the best of hypertension treatment phase $=0.366 \times 1+0.280 \times 1+0.354 \times 2=1.35$.

Combination the current study and previous researches, it showed that level one was the best treatment range for hypertension (Table 5).

Table 5. The result of relevant analyze of different patients' systolic pressure, diastolic pressure, anxiety, depression and personality of different age group $(n=956)$.

\begin{tabular}{lllllll}
\hline & $\begin{array}{l}\text { Systoli } \\
\text { c } \\
\text { pressur } \\
\text { e }\end{array}$ & $\begin{array}{l}\text { Diastoli } \\
\text { pressur } \\
\text { e }\end{array}$ & $\begin{array}{l}\text { BAI } \\
\text { total } \\
\text { score }\end{array}$ & $\begin{array}{l}\text { BDI } \\
\text { total } \\
\text { score }\end{array}$ & $\begin{array}{l}\text { E } \\
\text { standar } \\
\text { d score }\end{array}$ & $\begin{array}{l}\text { N } \\
\text { standar } \\
\text { d score }\end{array}$ \\
\hline Age & $0.601^{* *}$ & 0.104 & 0.497 & 0.358 & -0.205 & 0.446 \\
\hline Systolic pressure & - & $0.785^{* *}$ & $0.597^{* *}$ & $0.456^{*}$ & -0.325 & $0.576^{* *}$ \\
\hline diastolic pressure & $0.785^{* *}$ & - & $0.345^{*}$ & 0.247 & -0.156 & $0.243^{*}$ \\
\hline
\end{tabular}

${ }^{*} \mathrm{P}<0.05 ;{ }^{* *} \mathrm{P}<0.01$.

\section{Discussion}

Hypertension is a chronic symptom and a indicator of potential damage of various organs. It can not only cause further physiological damage to the patients, but also change the personality of patients.

According to the past experience, clinical doctors paid more attention to how to relieve the blood pressure of patients at a reasonable level to avoid the damage of target organ caused by hypertension. The high risk factors were shown as following written in hypertension prevention guidebook:

1) Diet rich in potassium but poor in sodium; 2) Overweight and obesity; 3) Drinking; 4) Mental stress; 5) Age, hypertension family history, lacking physical activities, etc. Among these high risk factors, mental stress is a neglected factor. According to some researches, the psychological symptoms could not be distinguished by non-psychiatric medical staff in comprehensive hospitals, which is one reason why the patients visit the hospital repeatedly. Only $13.4 \%$ neurotic patients can get treatment in the non-psychiatric department of a comprehensive hospital. In China, only $6.5 \%$ anxiety in outpatients could be correctly distinguished at an early stage. Slahl had proved that the consultation rate is higher in patients with panic disorder who asked for cardiovascular, digestive department and neurology doctors. The incidence of depression was $4.0 \%$ estimated by ICD-10, but only $1 / 5$ patients were distinguished by physicians. The distinguish rate of depression/anxiety disorder was $18.1 \%$ by physicians in Concord Hospital, which mean that non-psychiatric doctors showed a low accurate rate of distinguish and cure on depression/anxiety disorder. 597 cases in Shanghai showed that physicians had a mere $5.9 \%$ distinguish rate [8-12]. However, physical illnesses accounted for a very high rate such as anxiety, depression accompanied with hypertension. Gerin et al. found that people blood pressure went up constantly and exhibited obvious differences compared with the same period, same region since some years ago after the stressor that the 9.11 incident happened in New York, 2001 [13]. Tsutsumi et al. found that, among Japanese industrial workers, the risk of hypertension was 3 times higher in these under high stress level than with low stress level in a prospective study carried out $25 \mathrm{y}$ ago [14]. Yang et al. observed that the hypertension rate was $14 \%$ among people who worked less than $40 \mathrm{~h}$ a week, while it was $17 \%$ among those worked $41-50 \mathrm{~h}$ a week, and it was $29 \%$ more than $50 \mathrm{~h}$ a week in California physical examination data [15]. According to some foreign researches, incident rate of depression was $35.4 \%$ among hypertension patients [16]. Markovitz et al. did a 20 y follow-up visit among 1123 people with normal hypertension and found that anxiety and panic attack, anger emotion and inhibition of emotional vent could dramatically increase the hypertension occur rate among middle-aged male. Jonas did a follow-up inspection on 2992 people without hypertension at the beginning for 7 to 16 $\mathrm{y}$ and the result showed that anxiety and depression were both independent predictors of hypertension occurrence and related to hypertension treatment [17]. Boswort et al. did a cross sectional study on 29 elderly patients with hypertension for $3 \mathrm{y}$ and found that hypertension was correlated with depression, higher stress and low social support [18].

In our study, the higher hypertension level, the more serious psychological symptoms. The psychological symptoms weren't obvious until hypertension level exceeded grade 2 . We considered that level 1 was the best stage for treating hypertension.

Primary hypertension was interacted with the psychological factors and the personality characteristics, as well as the high risk period was mainly in old age stage. Those excitable elder hypertension patients showed more fluctuant blood pressure, and two factors were interacted with each other. The age and systolic blood pressure are positively related with a correlation coefficient of 0.601 in hypertension patients. Xiaoyun et al. [19] did an epidemiological analysis on hypertension in 51239 physical examination population, and found that the total incidence of hypertension was $23.73 \%$ in 2010 . Besides, analysis of the incidence rate in different age groups showed that the incidence rate of hypertension rose up with the increase of age. And the rate was 4.31 times higher in the old group than the youth group.

Besides, age and systolic blood pressure were positively related with anxiety in hypertension patients, and their depression score, correlation coefficient were 0.7850 .597 , $\mathrm{P}<0.05$ respectively; systolic blood pressure were positively 
related with mood $\mathrm{N}$ score in hypertension patients. Jonas et al. did a follow-up inspection on 2992 people without hypertension at the beginning for 7 to $16 \mathrm{y}$, and the result showed that anxiety and depression were both independent predictors of hypertension occurrence and related to hypertension treatment [20]. Multiple stepwise regression analysis was conducted to compare systolic blood pressure, diastolic blood pressure, personality and depression score in hypertension patients of different age groups, which indicated that the diastolic blood pressure came into regression equation, and $\mathrm{N}$ norm, the $\mathrm{B}$ value was over 0.6 , having statistical significance $(\mathrm{P}<0.05)$. This indicated that the higher systolic blood pressure is, the more unstable mood is, and more serious the anxiety and depression is in hypertension patients. Qingrong had done a research on hypertension patients and depression correlation in Chongqing, and the research indicated that the SAS and SDS score and anxiety depression incidence were obviously higher than control group and the norm for hypertension patients in Chongqing, which suggested that hypertension and anxiety depression were serious [21].

To sum up, the identification of psychological factors and symptoms should be taken into consideration during the process of diagnosis and treatment of primary hypertension. Regular medication is necessary for hypertension, but interact effect caused by psychological factors should also be valued. The psychological intervention should be strengthened especially for the middle and old age people, and active psychotherapy should be carried out to reign the blood pressure. Of course, it doesn't mean that every hypertension patients should receive psychological intervention, but the tailored time and method should be chosen for psychological intervention. Besides, due to the limited number of sample size and data, the results were needed more studies to confirm. Due to social ethics limitation, randomized controlled study, a better method proving the opinion of this research, cannot be carried out.

\section{References}

1. Carretero OA, Oparil S. Essential hypertension. Part I: Definition and etiology. Circulation 2000; 101: 329-335.

2. China Inhabitant Nutrition and Health Condition Investigation Technology Executive Team. A description on the Chinese national nutrition and health survey in 2002. Chin J Epidemiol 2005; 26: 478-484.

3. Wu EL, Chien IC, Lin CH, Chou YJ, Chou P. Increased risk of hypertension in patients with major depressive disorder: a population-based study. J Psychosom Res 2012; 73: 169-174.

4. Ginty AT, Crroll D, Roseboom TJ, Phillips AC, de Rooij SR. Depression and anxiety are associated with a diagnosis of hypertension 5 years later in a cohort of late middle-aged men and women. J Hum Hypertens 2013; 27 : 187-190.

5. Ford DE, Mead LA, Chang PP, Cooper-Patrick L, Wang NY, Klag MJ. Depression is a risk factor for coronary artery disease in men. Arch Intern Med 1998; 158: 1422-1426.

6. Wang XD, Jiang CQ, Ma H. The mental health scale handbook. Beijing: China Mental Health Periodical Office 2010.

7. Qian MY, Wu GC, Zhu RC, Zhang Z. The revision of Eysenck Personality Questionnaire Simplified Scale (EPQ-RSE). J Psychol 2000; 32: 317-323.

8. Ma LH, Hua QZ, Ni CP, Wang B. Investigation of Xi'an comprehensive hospital outpatients with neurotic disorder prevalence rate, doctor nurse and patient. The Fourth Military Med Univ 2012; 20-21.

9. Lu J, Li SW, Wei J. Comprehensive hospital outpatient's patient's depression/anxiety investigation. China Concord Med Univ 2008; 55-56.

10. Slahl SM. Management of patients with depression associated with anxiety symptom. J Clin Psychiatry 1997; 58: 19-26.

11. Wang PS, Lane M, Olfson M, Pincus HA, Wells KB, Kessler RC. Twelve-month use of mental health services in the United States: results from the National Comorbidity Survey Republication. Arch Gen Psychiatry 2005; 62: 629-640.

12. Zhang MY. Attention should be paid to the comprehensive hospital diagnosis and treatment of mental disorders. Chin Med J 1999; 79: 325-326.

13. Gerin W, Chaplin W, Schwartz JE, Holland J, Alter R, Wheeler R, Duong D, Pickering TG. Sustained blood pressure increase after an acute stressor: the effects of the 11 September 2001 attack on the New York City World Trade Center. J Hypertens 2005; 23: 279-284.

14. Tsutsumi A, Kayaba K, Tsutsumi K, Igarashi M. Association between job strain and prevalence of hypertension: a cross sectional analysis in a Japanese working population with a wide range of occupations: the Jichi Medical School cohort study. Occup Environ Med 2001; 58: 367-373.

15. Yang H, Schnall PL, Jauregui M, Su TC, Baker D. Work hours and self-reported hypertension among working in California. Hypertension 2006; 48: 744-750.

16. Yang PT, Lin L, Yuan $H$. The relationship between psychological, behavioural factors and primary hypertension. Med Rev 2007; 13: 1485-1488.

17. Markovitz JH, Jonas BS, Davidson K. Psychologic factors as precursors to hypertension. Curr Hypertens Rep 2001; 3: $25-32$.

18. Bosworth HB, Bartash RM, Olsen MK, Steffens DC. The association of psychosocial factors and depression with hypertension among older adults. Int J Geriatr Psychiatry 2003; 18: 1142-1148.

19. Zhao XY, Lu YG, Zhao HL, Wang JM, Song GY. Hebei province 51239 check-up crowd hypertension epidemiological analysis. J Gerontol Chin 2013; 33: 4818-4820.

20. Jonas BS, Franks P, Ingram DD. Are symptoms of anxiety and depression risk factors for hypertension? Longitudinal 
evidence from the National Health and Nutrition Examination Survey I Epidemiologic Follow up Study. Arch Fam Med 1997; 6: 43-49.

21. Le QR. Relationship survey in hypertensive patients with anxiety and depression in Chongqing. Chongqing Med Univ 2009; 1-3.

\section{${ }^{*}$ Correspondence to}

Li-Mei Xu
First Affiliated Hospital of Guangdong Pharmaceutical University

Guangzhou

China 